\title{
Causes and management of secondary postpartum haemorrhage in a tertiary medical college hospital in Bangladesh
}

\author{
Kamrun Nessa*, Sumia Bari, Sanjida Khan, Ferdowsi Sultana, Tania Akbar
}

Department of Obstetrics and Gynecology, Enam Medical College and Hospital, Savar, Dhaka, Bangladesh

Received: 24 April 2017

Accepted: 22 May 2017

*Correspondence:

Dr. Kamrun Nessa,

E-mail: Knessa3@gmail.com

Copyright: () the author(s), publisher and licensee Medip Academy. This is an open-access article distributed under the terms of the Creative Commons Attribution Non-Commercial License, which permits unrestricted non-commercial use, distribution, and reproduction in any medium, provided the original work is properly cited.

\begin{abstract}
Background: Globally postpartum haemorrhage remains a leading cause of maternal death. It affects only $1-2 \%$ of postnatal women. This low incidence of secondary PPH and linkage to maternal morbidity rather than mortality was the reason for the little attention among obstetricians, but it is recently gaining importance and interest with the increase morbidity and mortality related to secondary $\mathrm{PPH}$.

Methods: A retrospective study was conducted on the diagnosed patients of secondary PPH admitted in Enam Medical College and Hospital, Dhaka, Bangladesh, from January 2015 to December 2016. Among 33 cases of secondary PPH age of the patients, parity, mode of delivery, causes and management were noted from medical records. All data was analyzed by SPSS16.

Results: Among 33 patients 14 (42.4\%) were primi and 19 (57.6\%) were multipara, age between 18 to 38 years, majority admitted 2nd and 3rd week after delivery. Among 33 patients $12 \%$ delivered vaginally at home and $30 \%$ vaginally at hospital and 58\% undergone LUCS. We found 34\% retained bits of placenta, $27 \%$ uterine wound dehiscence, $24 \%$ retained clots and 15\% endometritis as causes. Less than 3 units blood needed in $22(66.7 \%)$ patients and $11(33.3 \%)$ needed more than 3 units. About $6(18 \%)$ patients were treated conservatively, MVA were needed in $18(55 \%)$ patients, repair of wound in $4(12 \%)$ and TAH was in $5(15 \%)$.

Conclusions: Secondary PPH is increasing may result in significant maternal morbidity as well as mortality. More study needed to identify the risk factors and causes to reduce maternal mortality and morbidity.
\end{abstract}

Keywords: MVA, Secondary PPH, TAH, Wound Dehiscence

\section{INTRODUCTION}

Secondary postpartum haemorrhage is defined as commencing per vaginal bleeding more than 24 hours following birth and during the following 6 weeks. ${ }^{1,2}$ It affects only $1-2 \%$ of postnatal women. This low incidence of secondary PPH and linkage to maternal morbidity rather than mortality was the reason for the little attention among obstetricians, but it is recently gaining importance and interest with the increase morbidity and maternal deaths because of this condition. ${ }^{3}$ The primary danger for patient is that bleeding in the majority occurs between 1 and 2 weeks after delivery., ${ }^{4,5}$
Globally, postpartum haemorrhage $(\mathrm{PPH})$ remains a leading cause of maternal deaths. ${ }^{6}$ However, in many low and middle-income countries, there is scarcity of information on magnitude of and risk factors for secondary postpartum haemorrhage. The highest burden is experienced in low-income countries. ${ }^{7,8}$ The jeopardy of $\mathrm{PPH}$ is rising with the secondary form of $\mathrm{PPH}$ (abnormal excessive bleeding from the birth canal, mostly uterus, occurring between 24 hours and 6 weeks postpartum) when women are already discharged home. PPH is a widely underestimated obstetric problem with variable occurrence and severity when diagnosed. ${ }^{9}$ The most common aetiological factors are retained products 
of conception and subinvolution of placental site/endometritis. A rare cause is partial or complete dehiscence of the lower uterine segment incision. ${ }^{10}$

We assessed the most common aetiology and management pattern among admitted patient of secondary postpartum haemorrhage in Enam Medical College and Hospital in the study period.

\section{METHODS}

This retrospective study was conducted on the diagnosed patients of secondary postpartum haemorrhage admitted in Enam medical college hospital, Savar, Dhaka, Bangladesh, during the period of January 2015 to December 2016. During these months 33 cases of secondary postpartum haemorrhage admitted in this hospital. Age of the patients, parity, and mode of delivery, causes and management of these patients were noted from medical and surgical records of the patients. Exclusion criteria were patient with history of bleeding disorders and those on anticoagulant.

Pulse rate was measured through the standard method of pulse rate counting and blood pressure was taken with the aneroid manometer. Per vaginal bleeding was measured by counting of sanitary pad soaked with blood, haemoglobin level and need of blood transfusion. Study was ethically approved by Ethical Review committee of Enam Medical College and Hospital. All data was entered in SPSS16 and analyzed through it.

\section{RESULTS}

In this study 33 patients of secondary postpartum haemorrhage were included. Among them 14 patients $(42.4 \%)$ were primi and $19(57.6 \%)$ were multipara, age of the patients were in between 18 to 38 years, mean age 25 years with SD \pm 4.8 years. Among 33 patients $2(6.1 \%)$ patients were admitted on $1^{\text {st }}$ week after delivery, 11 $(33.3 \%)$ were admitted on $2^{\text {nd }}$ week after delivery, 15 $(45.5 \%)$ were admitted on $3^{\text {rd }}$ week after delivery and 5 $(15.2 \%)$ were admitted on $4^{\text {th }}$ week. Regarding mode of delivery $12 \%$ delivered vaginally at home, $30 \%$ delivered vaginally at hospital and $58 \%$ undergone LUCS. All patients suffered from tachycardia and hypotension. We found $34 \%$ postpartum heamorrhage occurs due to retained bits of placenta, $27 \%$ due to uterine wound dehiscence, $24 \%$ due to retained clots and $15 \%$ due to endometritis (subinvolution of placental site). About 22 $(66.7 \%)$ patients needed less than 3 units of blood transfusion and $11(33.3 \%)$ needed more than 3 units of blood transfusion. About $6(18 \%)$ patients were improved by conservative treatment by giving broad spectrum injectable antibiotics, blood transfusion and intravenous fluid infusion.

Manual Vacuum Aspiration were done in 18 (55\%) patients, laparatomy followed by repair of uterin wound were done in $4(12 \%)$ patients and total abdominal hysterectomy was performed in $5(15 \%)$ patients. Only 2 patients need ICU support.

No mortality because of secondary postpartum heamorrhage was reported in this study period.

Table 1: Age distribution of patients of secondary postpartum haemorrhage.

\begin{tabular}{|lll|}
\hline Age & Frequency & Percent \\
\hline Less than 25 years & 24 & 72.7 \\
\hline 25-35 years & 8 & 24.2 \\
\hline More than 35 years & 1 & 3.0 \\
\hline Total & 33 & 100.0 \\
\hline
\end{tabular}

Table 1 shows distribution of age of the patients of secondary postpartum haemorrhage. Age less than 25 years was $72.7 \%$ which is significant in number $25-35$ years were $24.2 \%$, $3 \%$ were more than 35 years of age.

Table 2: Distribution of study patients according to parity.

\begin{tabular}{|lll|}
\hline Parity & Frequency & Percent \\
\hline Primi & 14 & 42.4 \\
\hline Multi & 19 & 57.6 \\
\hline Total & 33 & 100.0 \\
\hline
\end{tabular}

Table 2 shows the distribution of parity among study groups. Among 33 patients, primi were (42.4\%) and $(57.6 \%)$ were multipara women.

Table 3: Distribution of patients according to the day of admission following delivery.

\begin{tabular}{|c|c|c|}
\hline Day of Admission & Frequency & Percent \\
\hline 2 to 7 days & 2 & 6.1 \\
\hline 8 to 14 days & 11 & 33.3 \\
\hline 15 to 21 days & 15 & 45.5 \\
\hline 22 to 28 days & 5 & 15.2 \\
\hline Total & 33 & 100.0 \\
\hline
\end{tabular}

Table 3 shows distribution of day of admission following delivery. $6.1 \%$ patients were admitted within 2 to 7 days of delivery, $33.3 \%$ were within 8 to 14 days, $45.5 \%$ were within 15 to 21 days, $15.2 \%$ were admitted within 22 to 28 days.

Table 4: Distribution of study subjects according to amount of blood needed for management purpose.

\begin{tabular}{|ll|l|}
\hline Blood needed & Frequency & Percent \\
\hline $1(<3$ units $)$ & 22 & 66.7 \\
\hline $2(>3$ units $)$ & 11 & 33.3 \\
\hline Total & 33 & 100.0 \\
\hline
\end{tabular}

Table 4 shows distribution of study subjects according to amount of blood needed for the management purpose. $66.7 \%$ patients needed less than 3 units blood transfusion 
and $33.3 \%$ patients needed more than 3 units of blood transfusion.

Table 5: Distribution of study subjects according to duration of stay in hospital.

\begin{tabular}{|ll|l|}
\hline Duration of stay in hospital & Frequency & Percent \\
$<5$ days & 24 & 73 \\
\hline$>5$ days & 9 & 27 \\
\hline
\end{tabular}

Table 5 shows length of hospital stay of the study group. Among 33 patients $24(73 \%)$ patients discharged within 5 days after admission but $9(27 \%)$ patients were discharged after 5 days of admission.

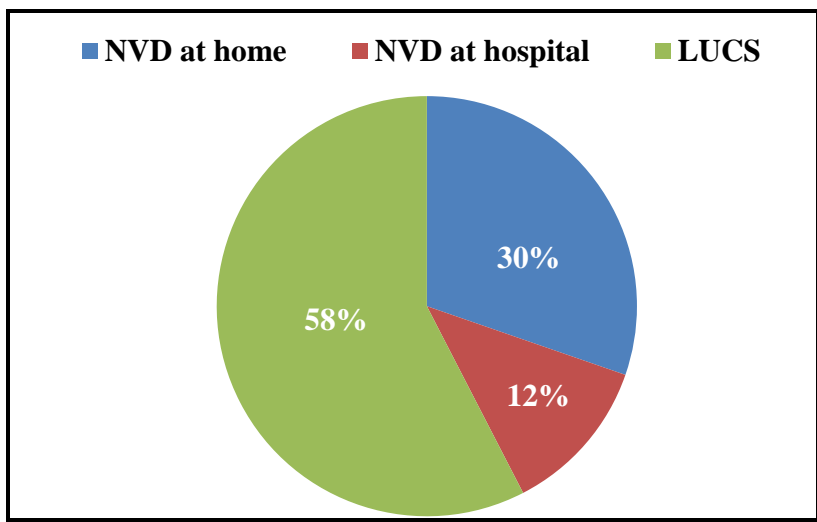

Figure 1: Distribution of study subjects according to mode of delivery.

Figure 1 shows mode of delivery of the patients. This study showing $10(30 \%)$ patients delivered vaginally at home whereas $4(12 \%)$ patients delivered vaginally at hospital. 19 (58\%) patients were delivered by LUCS which is significant in number.

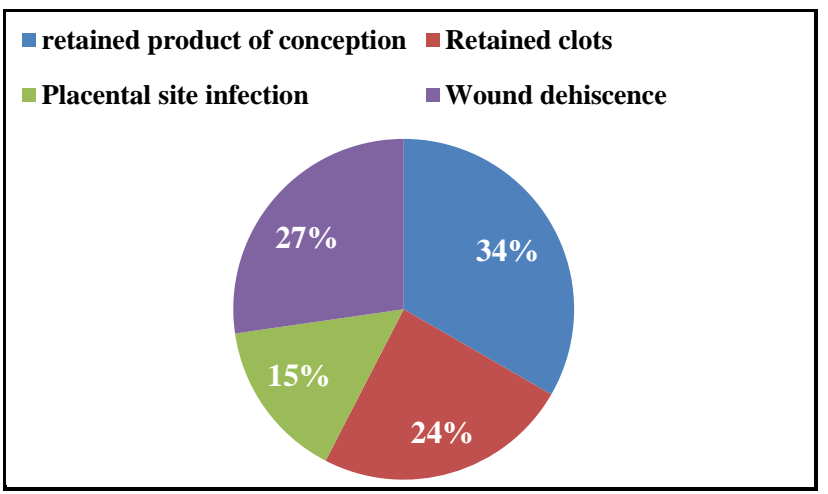

Figure 2: Distribution of study group according to causes of secondary postpartum haemorrhage (PPH).

Figure 2 shows distribution of study subjects according to the causes of secondary postpartum haemorrhage. Most common causes found retained bit of placenta $11(34 \%)$ patients. Retained clots were found in $8(24 \%)$ patients, endometritis/subinvolution of placental site were $5(15 \%)$ of cases. Uterine wound dehiscence was the causes of 9
(27\%) secondary postpartum haemorrhage in present study group.

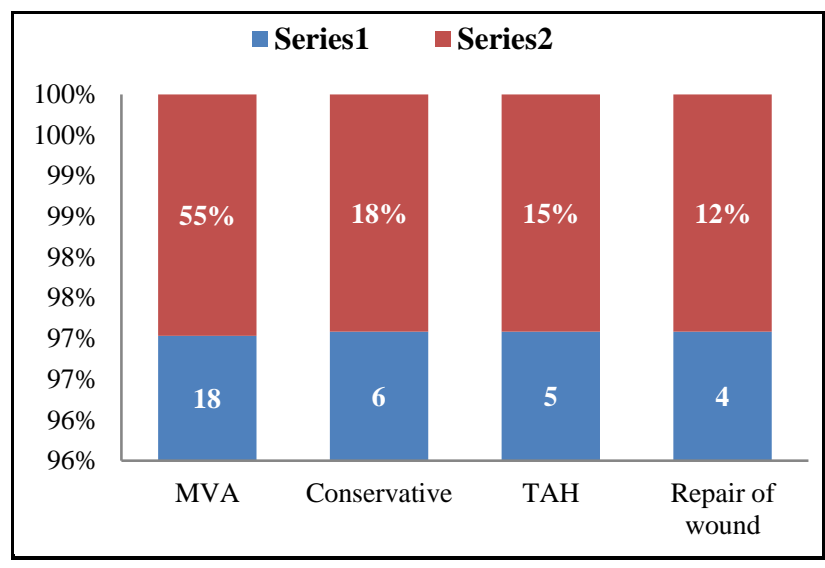

Figure 3: Distribution of study subjects according to the treatment options needed for the management of secondary postpartum haemorrhage.

Figure 3 shows distribution of study group according to the method of treatment. About 6 patients that is $18 \%$ patient were improved by conservative treatment (Broad spectrum antibiotics, blood transfusion, and correction of hypovolumia by intravenous fluid) and discharged to home without any further complications. Manual Vacuum Aspiration (MVA) were done for 18 (55\%) patients. $4(12 \%)$ patients were treated by repair of caesarean scar wound and $5(15 \%)$ needed Total abdominal hysterectomy (TAH) as caesarean scar were very bad and infected.

\section{DISCUSSION}

Postpartum haemorrhage is the leading cause of morbidity and mortality among pregnant ladies throughout the world causing 140,000 deaths each year globally, this corresponds to the one women dying in every 4 minutes and it is the 5th most common cause of maternal mortality throughout the world. ${ }^{11-16}$

In present study that all cases were either referred from local and rural hospital of another district. Some were admitted after taking conservative treatment in another centre. All were unbooked cases and also no deaths were reported during the study period; these findings were comparable with the findings in previous studies. ${ }^{11,12}$ In this study we found no relation of secondary postpartum haemorrhage with the parity but multi parity has been found as risk factor for secondary postpartum haemorrhage in other studies. ${ }^{17}$ It was noted that all women were conscious, hypotensive and tachycardic, these findings were consistent with the another study done on the same topic. ${ }^{12}$ This study also supported the fact that significant blood loss results in tachycardia and a measurable reduction in the blood pressure. ${ }^{18}$ The most common cause of secondary postpartum haemorrhage was retained uterine products same as found in past 
studies. ${ }^{5,19}$ We found $15 \%$ due to endometritis which is similar to another study. ${ }^{20}$ In this study we found $27 \%$ cases of uterine wound dehiscence which is more than the other previous study as because this is a tertiary care medical college hospital and all referral cases were admitted. ${ }^{10}$ In our centre we used manual vacuum aspiration for retained products of conception and retained clots, hysterectomy and repair of uterine wound for wound dehiscence, as the principal tools for the management of postpartum haemorrhage as indicated in another studies. ${ }^{11,19}$ There are another two studies showed $6.9 \%$ and $4.4 \%$ hysterectomy done for secondary postpartum haemorrhage which have the similarity with present study. ${ }^{21,22}$

Funding: No funding sources Conflict of interest: None declared

Ethical approval: The study was approved by the Institutional Ethics Committee

\section{REFERENCES}

1. Ratnam SS, Rauff M, Postpartum haemorrhage and abnormalities of the third stage of labour. In: Turnbull AC, Chamberlain G, eds. Obstetrics, Edinburgh: Churchill Livingstone;1989:867-875.

2. Still DK. Puerperal problems. In: James DK, Steer PJ, Weiner CP, GonicB, eds. High risk Pregnancy: Management options. London: W.B. Saunders; 1994:1183-92.

3. Farley NJ, Kohlmeier RE. A death due to subinvolution of the uteroplacental arteries. J Forensic Sci. 2011;56:803-5.

4. King PA, Duthie SJ, Dong ZG, Ma HK. Secondary postpartum haemorrhage. Aust N Z J Obstet Gynaecol. 1989;29:394-8.

5. Hoveyda F, MacKenzie IZ. Secondary postpartum haemorrhage: incidence, morbidity and current management. BJOG. 2001;108:927-30.

6. Say L, Chou D, Gemmill A, Tuncalp O, Moller AB, Daniels J, Gulmezoglu AM et al. Global causes of maternal death: a WHO systematic analysis. Lancet Glob Health. 2014;2:323-33.

7. Abou Zahr C. Global burden of maternal death and disability. Br Med Bull.2003;67:1-11.

8. Sheldon WR, Blum J, Vogel JP, Souza JP, Gülmezoglu AM, Winikoff B. Postpartum haemorrhage management, risks, and maternal outcomes: findings from the World Health Organization multicountry survey on maternal and newborn health. BJOG. 2014;121Suppl 1:5-13.

9. Zubor P, Kajo K, Dokus K, Krivus S, Straka L, Bodova KB et al. Recurrent secondary postpartum hemorrhages due to placental site vessel subinvolution and local uterine tissue coagulopathy. BMC Pregnancy and Childbirth. 2014;14(1):80.
10. Wagner MS, B'edard MJ. Postpartum uterine wound dehiscence: a case report. J Obstet Gynecol Canada. 2006;28(8):713-5.

11. Sheikh L, Najmi N, Khalid U, Saleem T. Evaluation of compliance and outcomes of a management protocol for massive postpartum hemorrhage at a tertiary care hospital in Pakistan. BMC Pregnancy Childbirth. 2011;11(1):28.

12. Krishna H, Chava M, Jasmine N, Shetty N. Patients with postpartum hemorrhage admitted in intensive care unit: Patient condition, interventions, and outcome. J Anaesthesiol Clin Pharmacol. 2011;27(2):192.

13. Condous G, Arulkumaran S. Medical and conservative surgical management of postpartum hemorrhage. J Obstet Gynecol Can. 2003;25(11):931.

14. Csorba R. Management of post partum haemorrhage. Orvosi Hetilap. 2012;153(17):643.

15. Rath W, Hackethal A, Bohlmann M. Second-line treatment of postpartum haemorrhage (PPH). Arch Gynecol Obstet. 2012;286(3):549-61.

16. Medical News and Events. Fact sheet: Management of postpartum haemorrhage. Available at http://www.drplace.com/Management_of_postpartu $\mathrm{m} \_$hemorrhage.16.22850.htm. Accessed on 14 April 2017.

17. Jaleel R, Khan A, Post-partum haemorrhage-a risk factor analysis. Mymensingh Med J. 2010;19(2):2829.

18. B-Lynch C. Postpartum Hemorrhage: A Comprehensive Guide to Evaluation, Management and Surgical Intervention. Sapiens Publishing; 2006.

19. Weisbrod AB, Sheppard FR, Chernofsky MR, Blankenship CL, Gage F, Wind G et al. Emergent management of postpartum hemorrhage for the general and acute care surgeon. World J Emerg Surg. 2009;4:43.

20. Edhi MM, Aslam HM, Naqvi Z, Hashmi H. Post partum hemorrhage: causes and management. BMC research notes. 2013;6(1):236.

21. Kittur S, Swetha D. Emergency peripartum hysterectomy- a study in tertiary care centre and medical college in Hubli, North Karnataka, India. Int J Reprod Contracep Obstet Gynecol. 2016;5:10971101.

22. Shirodker SD, Pandey A, Yadav S. Emergency obstetric hysterectomy: review at atertiary care hospital. Int J Reprod Contracept Obstet Gynecol. 2016;5:3811-4.

Cite this article as: Nessa K, Bari S, Khan S, Sultana F, Akbar T. Causes and management of secondary postpartum haemorrhage in a tertiary medical college hospital in Bangladesh. Int J Reprod Contracept Obstet Gynecol 2017;6:2694-7. 